\title{
The Innervated Distally Based First Dorsal Metatarsal Artery Flap with a Wide Pedicle for Reconstruction of a Great Toe Defect
}

\author{
Yohan Lee, MD*, Young Ho Lee, MD, Min Bom Kim, MD, Jisu Park, MD, Goo Hyun Baek, MD
}

Department of Orthopedic Surgery, Seoul National University Hospital, Seoul, Korea

\begin{abstract}
Background: It is difficult for surgeons to reconstruct soft tissue defects of the great toe. This report aims to evaluate the utility and efficacy of innervated distally based first dorsal metatarsal artery (FDMA) flap with a wide pedicle for reconstruction of soft tissue defects of the great toe.

Methods: This is a retrospective report. Between January 2015 and December 2017, six cases of skin defect of the great toe were reconstructed with an innervated distally based FDMA flap with a wide pedicle. One case was excluded in this report because of chronic pain on the metatarsophalangeal joint due to osteoarthritis before the injury. A total of five cases were evaluated for flap survival and sensory recovery. The sensory recovery was investigated by two-point discrimination and Semmes-Weinstein monofilament tests. The average age of the selected patients was 40 years (range, 36 to 56 years), and the average size of the defect in the toe was $8.3 \mathrm{~cm}^{2}$ (range, 4 to $13.8 \mathrm{~cm}^{2}$ ). The average follow-up period was 29.4 months (range, 18 to 38 months).

Results: All patients survived without any complications. The average two-point discrimination test value was $8.0 \pm 0.89 \mathrm{~mm}$ (range, 7 to $9 \mathrm{~mm}$ ), and the average value obtained from the Semmes-Weinstein monofilament test was $4.53 \pm 0.33$ (range, 4.17 to 4.93 ). The average residual pain score evaluated with a visual analog scale was 1 (range, 0 to 2). Two patients complained of stiffness in the great toe below $30^{\circ}$ of total range of motion during the early stages after surgery, but this stiffness gradually improved after rehabilitation. The average range of motion of three patients with a remaining metatarsophalangeal joint after surgery was $80^{\circ}$ (range, $70^{\circ}$ to $\left.90^{\circ}\right)$. All five cases could walk regularly without any unique footwear at the final follow-up.

Conclusions: The innervated distally based FDMA flap with a wide pedicle could be a good alternative method for repair of soft tissue defects of the great toe.
\end{abstract}

Keywords: Great toe, Soft tissue defect, First dorsal metatarsal artery, Perforator flap

It is challenging for surgeons to treat soft tissue defect of the great toe. The great toe is subjected to $60 \%$ of the load applied to the entire set of toes while walking. ${ }^{1)}$ The loss

${ }^{*}$ Current affiliation: Department of Orthopedic Surgery, SMG-SNU Boramae Medical Center, Seoul, Korea

Received December 12, 2018; Revised February 12, 2019; Accepted February 18, 2019

Correspondence to: Young Ho Lee, MD

Department of Orthopedic Surgery, Seoul National University Hospital, 103 Daehak-ro, Jongno-gu, Seoul 03080, Korea

Tel: +82-2-2072-0894, Fax: +82-2-764-2718

E-mail: orthoyh|@snu.ac.kr or shortening of the great toes has a significant impact on walking ability, which in turn leads to deformities in the other toes and ulcers. ${ }^{2)}$ Therefore, it is recommended that the surgeon should try to preserve the length of the great toe as much as possible while reconstructing the defect. Furthermore, vital structures such as tendons and bones can be easily exposed because they are located in close proximity to the skin. There are limited sources of soft tissues that can be used for reconstruction. ${ }^{3)}$ The flap must be strong enough for withstanding shoe friction and bearing weight, and restoration of the sensorial and protective functions of the toe is required to prevent recurrent ulceration while walking. ${ }^{4}$ 
Lee et al. Innervated Distally Based First Dorsal Metatarsal Artery Flap

Clinics in Orthopedic Surgery • Vol. 11, No. 3, $2019 \bullet$ www.ecios.org

The first dorsal metatarsal artery (FDMA) flap has been useful in the reconstruction of the defects on the dorsomedial side of the distal foot. The initial report of the FDMA flap was published by McCraw and Furlow ${ }^{5}$ in 1975. A distally based FDMA flap that was used to reconstruct the defects of the great toe, as well as the first ray defects, was developed by Ishikawa et al. ${ }^{6}$ and Bharathwaj and Quaba. ${ }^{7)}$ It is both thin and sufficiently strong, similar tissue at the site of the defect. It can reach the distalmost ends of the foot, even those that cannot be reached by other locoregional flaps. ${ }^{3)}$ The success rate of a distally based FDMA flap is inaccurate owing to the small number of cases reported in the literature. There have been no reports on complete necrosis, and the complication rate varies from $0 \%$ to $28.5 \%{ }^{3,7-9)}$ This suggests that even if FDMA flaps are reliable, small differences in the procedure can result in complications. Above all, the application of an innervated flap based on the FDMA flap design has not been carried out previously.

We newly designed an innervated FDMA flap with a wide pedicle. In comparison with the conventional FDMA flap, our flap was modified in two aspects. First, an innervated flap was constructed by connecting the medial dorsal cutaneous nerve in the FDMA flap to the proper plantar digital nerve in the defect site. Second, a wide pedicle was used to increase the survival rate. In this study, we aimed to evaluate the utility and effectiveness of the innervated distally based FDMA flap with a wide pedicle in great toe soft tissue defect reconstruction.

\section{METHODS}

This study was approved by Institutional Review Board in Seoul National University Hospital (IRB No. H-1902029-1009) and the patient consent was exempted. This is a retrospective report of patients who underwent a reconstructive surgery with the innervated distally based FDMA flap with a wide pedicle for soft tissue defect of the great toe. There were three exclusion criteria: (1) patients with chronic pain in the great toe before the event of soft tissue defect due to previous surgery, injury or osteoarthritis; (2) medical conditions that can affect sensorial functions such as diabetes, spinal pathology, syphilis, and leprosy; and (3) anatomical abnormality of the FDMA on computed tomography (CT) angiography.

Between January 2015 and December 2017, six cases of skin defect of the great toe were reconstructed with the innervated distally based FDMA flap with a wide pedicle. One case was excluded in this report because of chronic pain on the metatarsophalangeal joint due to osteoarthritis before the injury. The five cases were evaluated for flap survival and sensory recovery (Table 1 ). The average period of follow-up was 29.4 months (range, 18 to 38 months),

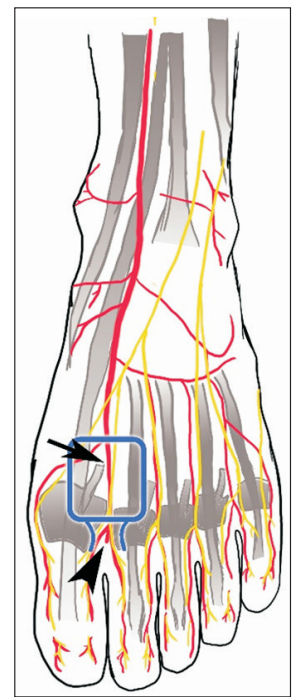

Fig. 1. The anatomy around the innervated distally based first dorsal metatarsal artery (FDMA) flap. Arrow: FDMA and medial dorsal cutaneous nerve, arrowhead: communicating branch between FDMA and plantar metatarsal artery.

\section{Table 1. Clinical Data of All Cases}

\begin{tabular}{cllllll}
$\begin{array}{c}\text { Patient } \\
\text { No. }\end{array}$ & Age $(\mathrm{yr}) / \mathrm{sex}$ & Side & \multicolumn{1}{c}{ Etiology } & Level of defect of great toe & Defect size $\left(\mathrm{cm}^{2}\right)$ & Combined injury \\
\hline 1 & $36 /$ Male & Left & Ischemic injury after surgery & Interphalangeal joint & $2.5 \times 3.5$ & Distal phalanx Fracture \\
\hline 2 & $42 /$ Male & Right & Crushing injury & Metatarsophalangeal joint & $3.2 \times 4.3$ & Distal phalanx Fracture \\
\hline 3 & $35 /$ Male & Right & Crushing injury & Proximal phalanx & $2.0 \times 2.0$ & Distal phalanx Fracture \\
\hline 4 & $56 /$ Female & Left & Squamous cell carcinoma & Metatarsophalangeal joint & $3.0 \times 3.5$ & None \\
\hline 5 & $31 /$ Male & Right & Crushing injury & Interphalangeal joint & $2.2 \times 2.0$ & None \\
\hline
\end{tabular}


Lee et al. Innervated Distally Based First Dorsal Metatarsal Artery Flap

Clinics in Orthopedic Surgery • Vol. 11, No. 3, $2019 \bullet$ www.ecios.org

and the average size of the defect was $8.3 \mathrm{~cm}^{2}$ (range, 4 to $13.8 \mathrm{~cm}^{2}$ ).

\section{Anatomical Relationship with Innervated FDMA Flap}

The overall anatomy around the FDMA is expressed in Fig. 1. The FDMA is mostly present, but some anatomical variations with regard to the source and course exist. Most FDMAs (80\%-96\%) originate from the dorsalis pedis (black arrow in Fig. 1), whereas only 9\% originate from the lateral tarsal artery. ${ }^{10,11)}$ The FDMA usually begins $10 \mathrm{~mm}$ distal and $5.5 \mathrm{~mm}$ dorsal to the first tarsometatarsal joint. The running course of FDMA varies in the sagittal plane, but it is commonly known that the FDMA runs dorsally along the transmetatarsal ligament. ${ }^{11)}$ Eighty-five percent of FDMA branches directed toward the plantar metatarsal artery that runs distally to the transmetatarsal ligament facilitates communication, ${ }^{3)}$ and the communicating branch can be used as a perforator flap, which usually exists between the first and second metatarsal heads (arrowhead in Fig. 1). On average, there are approximately three perforators for each FDMA. The largest perforator exists in the distal half of the FDMA. The average size of a perforasome area is reportedly $21.6 \times 47.6 \mathrm{~mm}^{2}{ }^{12}$ )

The sensation of the dorsum of the foot is dominated by nerve branches originating from the saphenous nerve, common peroneal nerve, and sural nerve. ${ }^{13-15)}$ The nerves usually involved in the application of a FDMA flap are the medial dorsal cutaneous nerves (black arrow in Fig. 1). ${ }^{13-15)}$ A majority of medial dorsal cutaneous nerves $(98 \%-100 \%)$ originate from the superficial peroneal nerves. ${ }^{15)}$ The nerve connected to the medial dorsal cutaneous nerve at the defect site is the proper plantar digital nerve, which originates from the medial plantar nerve. ${ }^{13)}$

\section{Surgical Procedure and Rehabilitation}

The FDMA and the communicating artery were identified in all cases by performing CT angiography before surgery. The surgery was performed by placing patients in the supine position under general or spinal anesthesia and by employing a pneumatic tourniquet. The defect site was fully irrigated with normal saline after antiseptic preparation. Debridement was performed by carefully avoiding any damage to neurovascular structures. The proper plantar digital nerve was exposed by carrying out careful dissection along with debridement. The size of the defect was measured, and the flap, including the pedicle and pivot site, was designed to match the size of the defect area on the dorsomedial side of the distal foot. An incision was made along the design by carefully avoiding damage to the dorsal cutaneous nerve. An additional zigzag incision, approximately measuring $2.5-\mathrm{cm}$ long, was made on the proximal area of the flap for uncovering the medial dorsal cutaneous nerve. The flap was dissected and elevated after cutting at the proximal part of the medial dorsal cutaneous nerve. The paratenon was left around the tendon for preventing adhesion, although the fascia was included in the flap. The pedicle that had a width similar to that of the flap was dissected including the fascia just above the muscle layer, like harvesting adipofascial flaps. The pedicle consisted of a perforator artery with accompanying efferent vein, subcutaneous tissue, and fascia, barring the skin and muscle. The dissection of the pedicle was stopped when it reached the intermetatarsal ligament for preventing injury to the communicating artery. The flap was pivoted to the defect site after confirming circulation of the flap by releasing the tourniquet. If the flap sufficiently covered the defect site, neurorrhaphy was performed between the proper plantar digital nerve and the medial dorsal cutaneous nerve. Tension-free suturing of the flap at the margin of the defect was carried out. The pedicle and donor sites were left open with or without suturing the loose skin in order to prevent vascular congestion. The open site was maintained by performing occlusive dressing daily after the initial surgery. A full-thickness skin graft was applied to the donor site and pedicle 2 weeks later. One week after the application of a full-thickness skin graft, the patient was recommended to gradually increase his walking frequency with the aid of a short leg splint. If there were no wound-related complications, the donor site was fully stitched out at 2 weeks after the application of a fullthickness skin graft. If patients experienced joint stiffness, they were asked to engage in self-rehabilitation exercises for both active and passive range of motions at least three times a day for $\geq 30$ minutes.

\section{Outcome Evaluation}

Flap survival was evaluated in terms of complete survival, partial necrosis, and total necrosis. The pain experienced by the patients during the last follow-up was measured using the 10-point visual analog scale (VAS; range, 0 to 10). Complications were defined as identified symptoms that can cause functional problems or warrant additional surgery. If there were remaining joints of the great toe after reconstruction, a total range of motion of joints was measured. The extent of sensory recovery was measured at the final visit. Sensory recovery was determined using two-point discrimination (2PD) and Semmes-Weinstein (SW) monofilament tests. All patients were subjected to the same test protocol. Both flap and normal sides were checked for comparison. A false application was randomly 
Lee et al. Innervated Distally Based First Dorsal Metatarsal Artery Flap

Clinics in Orthopedic Surgery • Vol. 11, No. 3, $2019 \bullet$ www.ecios.org

implemented between the actual tests to validate our results. The 2PD test measurements were objectively taken using the Touch test Two-Point Discriminator (North Coast Medical Inc., San Jose, CA, USA). This test measured the maximum short distance a patient felt, separated by two, at from $1 \mathrm{~mm}$ to $15 \mathrm{~mm}$. The SW monofilament test makes use of commercially available SW monofilaments (North Coast Medical Inc.). The thickness of the filaments, ranging between 1.65 and 6.65, was recorded by pushing the filament until it buckled.

\section{RESULTS}

All cases survived without any complications (Tables 2 and 3). The average $2 \mathrm{PD}$ value was $8.0 \pm 0.89 \mathrm{~mm}$ (range, 7 to $9 \mathrm{~mm}$ ), and the average SW monofilament test value was $4.53 \pm 0.33$ (range, 4.17 to 4.93 ). The average residual pain score measured by VAS was 1 (range, 0 to 2). Patients 2 and 4 were unable to measure the range of motion of the joint because there was no remaining joint in the great toe after surgery. Patients 1 and 3 complained of stiffness in the great toe below $30^{\circ}$ of total range of motion during the early stages after surgery, but this stiffness gradually improved after rehabilitation. The average of the total range of motion of the remaining joint was $80^{\circ}$ (range, $70^{\circ}$ to $90^{\circ}$ ) at the final follow-up (Table 3). There was no restriction of joint motion or pain by the scar of the donor or recipient site. All of five cases could walk regularly without any unique footwear at the final follow-up.

\section{Case: Patient No. 1}

A 36-year-old male patient visited hospital because of a distal phalanx fracture of the right great toe that occurred after a heavy object fell on his foot. K-wire pinning and roll wire fixation was conducted after a closed reduction at the hospital. He was referred to our hospital owing to the occurrence of ischemic necrosis on the great toe at 2 weeks after surgery (Fig. 2A). Debridement was performed, and the distal phalanx was amputated because it was nonviable (Fig. 2B). If primary closure by the surrounding tissue is

\section{Table 2. Result of Reconstruction 1}

\begin{tabular}{|c|c|c|c|c|c|c|c|c|c|}
\hline \multirow{2}{*}{$\begin{array}{l}\text { Patient } \\
\text { No. }\end{array}$} & \multirow{2}{*}{$\begin{array}{l}\text { Flap size } \\
\left(\mathrm{cm}^{2}\right)\end{array}$} & \multirow{2}{*}{$\begin{array}{l}\text { Coverage } \\
\text { of donor } \\
\text { site }\end{array}$} & \multirow{2}{*}{$\begin{array}{l}\text { Time between } \\
\text { injury and } \\
\text { operation }\end{array}$} & \multirow{2}{*}{ Survival of flap } & \multicolumn{2}{|c|}{ Two-point discrimination } & \multicolumn{2}{|c|}{ SW monofilament (size) } & \multirow{2}{*}{$\begin{array}{c}\text { Scar } \\
\text { contracture } \\
\text { of donor site }\end{array}$} \\
\hline & & & & & Flap (mm) & $\begin{array}{l}\text { Contralateral } \\
\text { side }(\mathrm{mm})\end{array}$ & Flap & $\begin{array}{l}\text { Contralateral } \\
\text { side }\end{array}$ & \\
\hline 1 & $2.5 \times 3.5$ & FTSG & $\begin{array}{l}10 \text { Days from } \\
\text { first surgery }\end{array}$ & Complete survival & 7 & 4 & 4.17 & 3.84 & None \\
\hline 2 & $3.2 \times 4.3$ & FTSG & 1 Day & Complete survival & 8 & 6 & 4.31 & 4.17 & None \\
\hline 3 & $2.0 \times 2.0$ & FTSG & 16 Hours & Complete survival & 9 & 6 & 4.93 & 4.17 & None \\
\hline 4 & $3.0 \times 3.5$ & FTSG & $\begin{array}{l}\text { Immediately after } \\
\text { excision of } \\
\text { the tumor }\end{array}$ & Complete survival & 7 & 4 & 4.93 & 3.61 & None \\
\hline 5 & $2.2 \times 2.0$ & FTSG & 12 Hours & Complete survival & 9 & 6 & 4.31 & 4.17 & None \\
\hline
\end{tabular}

SW: Semmes-Weinstein, FTSG: full-thickness skin graft.

\section{Table 3. Result of Reconstruction 2}

\begin{tabular}{ccccccc} 
Patient No. & Total range of motion of great toe $\left(^{\circ}\right)$ & Walking ability & Complication & Pain VAS & Follow-up period (mo) \\
\hline 1 & 90 & Unlimited & None & 0 & 2 \\
2 & $0^{*}$ & Unlimited & None & None & 2 & 38 \\
\hline 3 & 80 & Unlimited & None & 0 & 18 \\
4 & $0^{*}$ & Unlimited & None & 1 & 33 \\
\hline 5 & 70 & Unlimited & & \\
\hline
\end{tabular}

VAS: visual analog scale.

* There are no remaining joints to measure. 
Lee et al. Innervated Distally Based First Dorsal Metatarsal Artery Flap

Clinics in Orthopedic Surgery • Vol. 11, No. 3, $2019 \bullet$ www.ecios.org
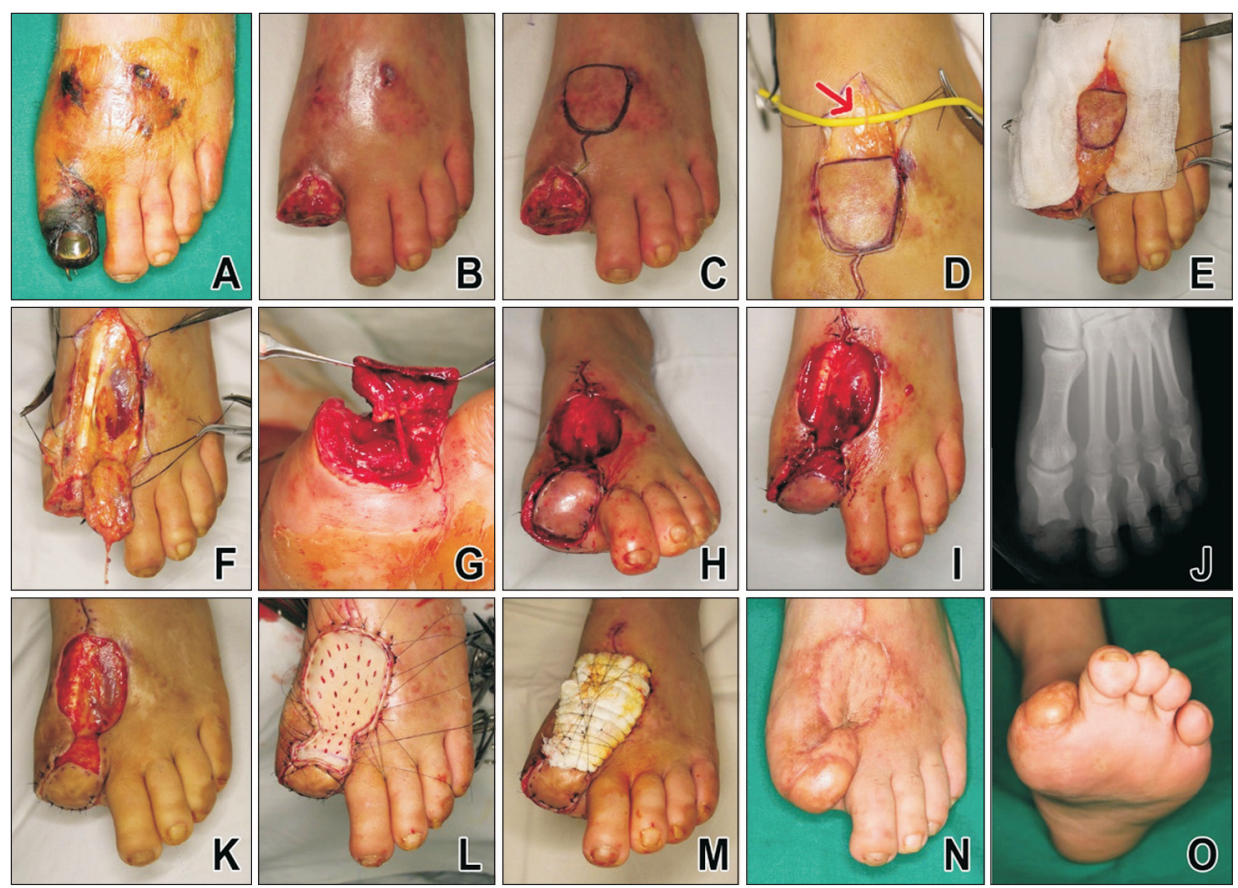

Fig. 2. (A) A 36-year-old male patient visited our hospital owing to the occurrence of ischemic necrosis on the great toe at 2 weeks after internal fixation on left great toe. (B) Debridement was performed, and the distal phalanx was amputated because it was nonviable. (C) The innervated reverse first dorsal metatarsal artery flap was designed on the dorsomedial part of the foot to match the size of the defect site. (D) The medial dorsal cutaneous nerve was found at the proximal area of the flap (arrow). (E) The wide adipofascial pedicle was dissected at the distal end of the flap. (F) The pedicle was dissected up to the intermetatarsal ligament, and the paratenon around the tendon was preserved. (G) Neurorrhaphy was performed between the plantar proper digital nerve at the defect site and the medial dorsal cutaneous nerve of the flap. $(\mathrm{H}$, I) The flap was placed at the defect site and sutured. (J) An immediate postoperative X-ray scan showed that the proximal phalanx remained intact along the entire length. (K) Two weeks after the flap coverage, granulation tissue developed. (L, M) A full-thickness skin graft was applied from the inguinal area. (N, 0) Thirty-eight months after the surgery, the flap was found to survive without necrosis.

to be attempted, then the need for shortening procedure or resection of the proximal phalanx becomes inevitable because the soft tissue exists at the same level as that of the proximal phalanx (Fig. 2B). The innervated FDMA flap with a wide pedicle was designed to preserve the length of the proximal phalanx. The flap was designed on the dorsomedial part of the foot to match the size of the defect site (Fig. 2C). The medial dorsal cutaneous nerve was found at the proximal area of the flap (indicated by the red arrow in (Fig. 2D). The wide pedicle was dissected at the distal end of the flap (Fig. 2E). The pedicle was dissected up to the intermetatarsal ligament, and the paratenon around the tendon was left as is (Fig. 2F). Neurorrhaphy was performed between the plantar proper digital nerve at the defect site and the medial dorsal cutaneous nerve of the flap (Fig. 2G). The flap was placed at the defect site and sutured (Fig. 2H and I). The occlusive dressing was performed on the open wound at the donor and pedicle sites. An immediate postoperative X-ray scan showed that the proximal phalanx remained intact along the entire length
(Fig. 2J). Two weeks after the flap coverage, granulation tissue developed (Fig. 2K). A full-thickness skin graft was applied from the inguinal area (Fig. 2L and M). Thirtyeight months after the surgery, the flap was found to survive without necrosis (Fig. $2 \mathrm{~N}$ and $\mathrm{O}$ ). The patient could also walk without experiencing any disability or pain.

\section{DISCUSSION}

Soft tissue reconstruction of the great toe can range from secondary intention ${ }^{16)}$ to primary closure, ${ }^{17)}$ skin graft, ${ }^{18)}$ locoregional flap, ${ }^{5,6,9,19-22)}$ and free flap. ${ }^{23,24)}$ Primary closure is possible if the defect size is small, but in many cases, shortening or trimming procedure of the bony structure is required owing to the absence of soft tissues close to the defect. ${ }^{17)}$ Skin grafts have limited durability, and they can be damaged during shoe friction or weight-bearing. ${ }^{25}$ Application of skin graft is inappropriate even when the tendon and bone are exposed. ${ }^{26,27)}$ Free flaps are useful in cases where the skin grafts are sufficiently large and when 
Lee et al. Innervated Distally Based First Dorsal Metatarsal Artery Flap

Clinics in Orthopedic Surgery • Vol. 11, No. 3, $2019 \bullet$ www.ecios.org

locoregional flaps are challenging to use or there is a need to rebuild the skin together with other structures such as bone and tendon. However, free flaps are technically challenging.

A locoregional fasciocutaneous flap is a useful method for the reconstruction of small-to-medium sized defects of a foot. It is easier and has a higher success rate in comparison with the free flap. It has similar properties as the tissues at the defect site, and thus has functional and aesthetical benefits. ${ }^{5,919-22,28)}$ The locoregional flap available for the treatment of the great toe defect includes distally based dorsalis pedis flaps, ${ }^{9)}$ distally based medial plantar flaps ${ }^{19)}$ distally based tibialis anterior flaps ${ }^{20)}$ and toe fillet flap. ${ }^{21)}$ If a toe fillet flap is applied, a sacrifice of the toe is inevitable because of its characteristics. ${ }^{21)}$ Other flaps are challenging to use because they are anatomically dissimilar to the tissues at the defect site or because they cannot reach the far distal end when the stump of the great toe remains. ${ }^{5,9,19-22,28)}$

In contrast, if an FDMA flap is used, it is possible to reach up to the far distal end because the pivot point is located distal to the transmetatarsal ligament. ${ }^{12,22,29)}$ It also has an aesthetical value because of being thin and durable. As per the published literature, ${ }^{3)}$ primary closure of the donor site is possible if the width of the flap is $<2.5 \mathrm{~cm}$. Bharathwaj and Quaba ${ }^{7)}$ reported that they could cover the defect site, ranging in area between $2.5 \times 5 \mathrm{~cm}^{2}$ and $5 \times$ $8 \mathrm{~cm}^{2}$, using an FDMA flap. In our study, we attempted to reach a coverage of $3.2 \times 4.3 \mathrm{~cm}^{2}$ and succeeded.

This study improved the traditional FDMA flap in two ways. First, an innervated flap was constructed by connecting the medial dorsal cutaneous nerve in the
FDMA flap to the proper plantar digital nerve in the defect site. Rith-Najarian ${ }^{30)}$ revealed that the minimum sensitivity of a foot's protective function is SW 5.07 monofilament. All cases of this study showed a higher sensitivity than SW 5.07, thereby demonstrating that the FDMA flap can sufficiently facilitate the restoration of sensorial functions to protective functions in the great toe. Second, a wide pedicle was made use of in the design of this flap. There are three advantages to using a wide pedicle. First of all, it does not cause any direct damage to the perforator during dissection. Second, concomitant venous network around the artery can be included in the pedicle, which can improve the venous return. Finally, the pedicle can function as an adipofascial flap. It is possible to leave the pedicle open without the exertion of any tension; this will help avoid the exertion of any constraints on blood circulation caused by skin suturing around the pedicle.

This study has some limitations. First, it is a small case series, and hence it was difficult to objectivity elucidate the outcomes and derive conclusions. Second, we could not make any comparisons with regard to sensorial recovery without performing neurorrhaphy for the flap used in our study. In conclusion, the innervated distally based FDMA flap with a wide pedicle could be a good alternative treatment for soft tissue defect of the great toe.

\section{CONFLICT OF INTEREST}

No potential conflict of interest relevant to this article was reported.

\section{REFERENCES}

1. Hughes J, Clark P, Klenerman L. The importance of the toes in walking. J Bone Joint Surg Br. 1990;72(2):245-51.

2. Quebedeaux TL, Lavery LA, Lavery DC. The development of foot deformities and ulcers after great toe amputation in diabetes. Diabetes Care. 1996;19(2):165-7.

3. Limthongthang R, Eamsobhana P. First dorsal metatarsal artery perforator flap to cover great toe defect. J Orthop Surg (Hong Kong). 2017;25(3):2309499017739497.

4. Reiffel RS, McCarthy JG. Coverage of heel and sole defects: a new subfascial arterialized flap. Plast Reconstr Surg. 1980;66(2):250-60.

5. McCraw JB, Furlow LT Jr. The dorsalis pedis arterialized flap: a clinical study. Plast Reconstr Surg. 1975;55(2):177-85.

6. Ishikawa K, Isshiki N, Suzuki S, Shimamura S. Distally based dorsalis pedis island flap for coverage of the distal portion of the foot. Br J Plast Surg. 1987;40(5):521-5.

7. Bharathwaj VS, Quaba AA. The distally based islanded dorsal foot flap. Br J Plast Surg. 1997;50(4):284-7.

8. Governa M, Barisoni D. Distally based dorsalis pedis island flap for a distal lateral electric burn of the big toe. Burns. 1996;22(8):641-3.

9. Russo A, Delia G, Casoli V, Colonna MR, Stagno d'Alcontres F. Dorsalis Pedis Adipofascial Perforator flap for great toe reconstruction: anatomical study and clinical applications. J Plast Reconstr Aesthet Surg. 2014;67(4):550-4.

10. Earley MJ, Milner RH. A distally based first web flap in the foot. Br J Plast Surg. 1989;42(5):507-11.

11. Kim JW, Choi YJ, Lee HJ, Yi KH, Kim HJ, Hu KS. Anatomic 
Lee et al. Innervated Distally Based First Dorsal Metatarsal Artery Flap

Clinics in Orthopedic Surgery • Vol. 11, No. 3, $2019 \bullet$ www.ecios.org

study of the dorsalis pedis artery, first metatarsal artery, and second metatarsal bone for mandibular reconstruction. J Oral Maxillofac Surg. 2015;73(8):1627-36.

12. van Alphen NA, Laungani AT, Christner JA, Lachman N, Carlsen BT, Saint-Cyr M. The distally based dorsal metatarsal artery perforator flap: vascular study and clinical implications. J Reconstr Microsurg. 2016;32(4):245-50.

13. Fares A, Kusnezov N, Dunn JC, et al. Predictability of lower extremity peripheral nervous anatomy. J Surg Orthop Adv. 2017;26(4):206-10.

14. Candan B, Albay S. Determination and classification of cutaneous innervation of the dorsum of the foot in foetal cadavers. Folia Morphol (Warsz). 2018;77(4):698-702.

15. Wahee P, Aggarwal A, Harjeet, Sahni D. Variable patterns of cutaneous innervation on the dorsum of foot in fetuses. Surg Radiol Anat. 2010;32(5):469-75.

16. Josty IC, Ramaswamy R, Laing JH. Vaccum assisted closure: an alternative strategy in the management of degloving injuries of the foot. Br J Plast Surg. 2001;54(4):363-5.

17. Aerden D, Vanmierlo B, Denecker N, Brasseur L, Keymeulen B, Van den Brande P. Primary closure with a filleted hallux flap after transmetatarsal amputation of the big toe for osteomyelitis in the diabetic foot: a short series of four cases. Int J Low Extrem Wounds. 2012;11(2):80-4.

18. Downs DM, Jacobs RL. Treatment of resistant ulcers on the plantar surface of the great toe in diabetics. J Bone Joint Surg Am. 1982;64(6):930-3.

19. Akita S, Mitsukawa N, Rikihisa N, et al. Reconstruction of the great toe using a pedicled medial plantar flap with anterograde venous drainage. Microsurgery. 2014;34(5):398403.

20. Dong JS, Peng YP, Zhang YX, Lim BH, Pho RW. Reverse anterior tibial artery flap for reconstruction of foot donor site. Plast Reconstr Surg. 2003;112(6):1604-12.
21. Sidon E, Shemesh S, Rosenthal Y, Heller S, Velkes S, Burg A. Medial forefoot fillet flap for primary closure of transmetatarsal amputation: a series of four cases. Foot (Edinb). 2017;33:53-6.

22. Lee JH, Dauber W. Anatomic study of the dorsalis pedisfirst dorsal metatarsal artery. Ann Plast Surg. 1997;38(1):505.

23. Kawamura K, Yajima H, Kobata Y, Shigematsu K, Maegawa N, Takakura Y. Coverage of big toe defects after wraparound flap transfer with a free soleus perforator flap. J Reconstr Microsurg. 2005;21(4):225-9.

24. Kim YH, Kim KH, Sung KY, Kim JT, Kim SW. Toe resurfacing with a thin thoracodorsal artery perforator flap. Microsurgery. 2017;37(4):312-8.

25. Myerson M. Split-thickness skin excision: its use for immediate wound care in crush injuries of the foot. Foot Ankle. 1989;10(2):54-60.

26. Attinger C. Use of skin grafting in the foot. J Am Podiatr Med Assoc. 1995;85(1):49-56.

27. Attinger C. Soft-tissue coverage for lower-extremity trauma. Orthop Clin North Am. 1995;26(2):295-334.

28. Kuntscher MV, Erdmann D, Homann HH, Steinau HU, Levin SL, Germann G. The concept of fillet flaps: classification, indications, and analysis of their clinical value. Plast Reconstr Surg. 2001;108(4):885-96.

29. Cheng MH, Ulusal BG, Wei FC. Reverse first dorsal metatarsal artery flap for reconstruction of traumatic defects of dorsal great toe. J Trauma. 2006;60(5):1138-41.

30. Rith-Najarian SJ, Stolusky T, Gohdes DM. Identifying diabetic patients at high risk for lower-extremity amputation in a primary health care setting: a prospective evaluation of simple screening criteria. Diabetes Care. 1992;15(10):1386-9. 